\title{
BAHASA INDONESIA DI THAILAND MENJADI MEDIA DIPLOMASI KEBAHASAAN DAN BUDAYADI ASEAN MELALUI PENGAJARAN BIPA
}

\author{
Refa Lina Tiawati $\mathbf{R}$ \\ Dosen Program Studi Pendidikan Bahasa dan Sastra Indonesia \\ STKIP PGRI Sumatera Barat \\ Email:riefhalina@gmail.com
}

\section{Submitted :10-05-2016, Reviewed:15-10-2016, Accepted:31-10- 2016http://dx.doi.org/10.22202/jg.2015.v1i1.1159}

\begin{abstract}
In the effort to introducing and consolidating Indonesian language to the world and ASEAN level, there are a few of options but teaching and mastering Bahasa Indonesia (BI). Through the teaching of Bahasa indonesia for foreign speaker (BIPA), it can be a media of language and culture diplomacy and brings indonesian language as lingua franca in ASEAN community, as happen in Thailand. Therefore, some efforts need to be done in order to realize that through the teaching of BIPA. to increase the interest in learning BI in abroad, to improve the image of the Indonesia as a nation and make BI as Lingua franca, which 1.System BIPA teaching abroad, 2) the material of BIPA, the BIPA learning is not always teach people about the language but also includes material about the culture and Indonesian literature. 3) the purposes of teaching BIPA, to prepare Indonesian language tobe lingua franca in the Asean community.
\end{abstract}

Keywords: BI teaching in Thailand, ASEAN community, teaching BIPA.

\begin{abstract}
Abstrak
Dalam upaya untuk memperkenalkan dan mengkonsolidasikan bahasa Indonesia ke dunia dan tingkat ASEAN, ada beberapa pilihan, tapi mengajar dan menguasai Bahasa Indonesia (BI). Melalui pengajaran Bahasa Indonesia untuk penutur asing (BIPA), itu bisa menjadi media bahasa dan diplomasi budaya dan membawa bahasa indonesia sebagai lingua franca di masyarakat ASEAN, seperti terjadi di Thailand. Oleh karena itu, beberapa upaya perlu dilakukan untuk menyadari bahwa melalui pengajaran BIPA. untuk meningkatkan minat belajar BI di luar
\end{abstract}


negeri, untuk meningkatkan citra Indonesia sebagai bangsa dan membuat BI sebagai Lingua franca, yang 1.Sistem BIPA mengajar di luar negeri, 2) materi BIPA, pembelajaran BIPA tidak selalu mengajarkan orang tentang bahasa tetapi juga mencakup materi tentang budaya dan sastra Indonesia. 3) tujuan pengajaran BIPA, untuk mempersiapkan bahasa Indonesia tobe lingua franca dalam komunitas Asean.

Kata kunci: pembelajaran BI di Thailand, ASEAN, mengajar BIPA.

\section{PENDAHULUAN}

Bangsa Indonesia adalah pemilik BI. Jati diri suatu bangsa dan martabat bangsanya terletak di tangan bangsa itu sendiri. Begitu juga halnya dengan jati diri suatu bangsa adalah bahasa. Negara Indonesia memiliki bahasa persatuan yaitu Bahasa Indonesia. BI yang merupakan bahasa persatuan sangat penting kedudukanya dalam kehidupan masyarakat Indonesia, ini juga harus diketahui oleh negara lain yang ingin mengenal Indonesia khusunya dalam BIPA. Pembelajar BIPA harus mengetahui bahwa BI memiliki nilai historis, nilai sosiologis, nilai politis dan estetika yang tidak dapat dilepaskana dari keberadaan bangsa Indonesia.

Fungsi BI itu sendiri bukan hanya sebagai lambang identitas bangsa dan sebagai bahasa nasional. Tapi BI sebagai alat pemersatu berbagai masyarakat yang berbeda latar belakang sosial, budaya,dan bahasa daerahnya yang merupakan alat komunikasi ke seluruh pelosok Nusantara. Selain itu, peningkatan fungsi BI menjadi bahasa Internasional, telah diatur dalam Undang-Undang Republik Indonesia
Nomor 24 Tahun 2009 pasal 44. Oleh karena itu, melalui bahasa bangsa Indonesia dapat mengunakan bahasa sebagai media diplomasi kebahasaan dan budaya untuk membangun citra positif masyarakatnya dan dapat mempromosikan budaya Indonesia di dunia Internasionalsalah satunya ASEAN.

Negara Indonesia merupakan salah satu anggota ASEAN. Antara Indonesia dan ASEAN memiliki berbagai bentuk kerja sama di bidang pembangunan dan percepatan pemajuan ekonomi, antara lain perluasan perdagangan, investasi, kepariwisataan, ilmu pengetahuan dan teknologi, serta dibidang pendidikan. ASEAN juga bertekad untuk memperkuat persatuan dan saling pengertian terhadap perbedaan kebudayaan, sejarah, agama, dan peradaban demi terwujudnya Komunitas ASEAN (ASEAN community) tahun 2015. Untuk meningkatkan hubungan diplomasi antara Indonesia dan ASEAN, diantaranya hubungan bilateral yang terjadi antara Indonesia dan Thailand, pendidikan atau pengajaran BI di 
Thailand sebagai bahasa asing telah menjadi salah satu tujuan dari kerjasama tersebut.Adanyahubungan bilateral yang terjalin antara Indonesia dan Thailand khususnya kerjasama pada bidang pendidikan dan kebudayaan, yang menjadikan BI diteriman oleh masyarakat Thailand dengan tangan terbuka. Sampai saat ini yang penulis ketahui, di Thailand kurang lebih ada delapan universitas yang membuka mata kuliah pilihan $\mathrm{BI}$, salah satunya di Universitas Naresuan (Naresuan University/ NU) ditempat penulis mengajar saat itu.

Masalah untuk memulihkan citra Indonesia di mata ASEAN dan dunia, untuk meningkatkan minat belajar BI di luar negeri dan untuk menjadikan BI sebagai bahasa lingua franca di ASEAN. Ada beberapa hal yang mesti diperbaiki dan di upayakan melalui BIPA, yaitu 1) sistem pegajaran BIPA di luar negeri, 2)materi BIPA dan 3) tujuan pengajaran BIPA.

\section{METODE PENELITIAN}

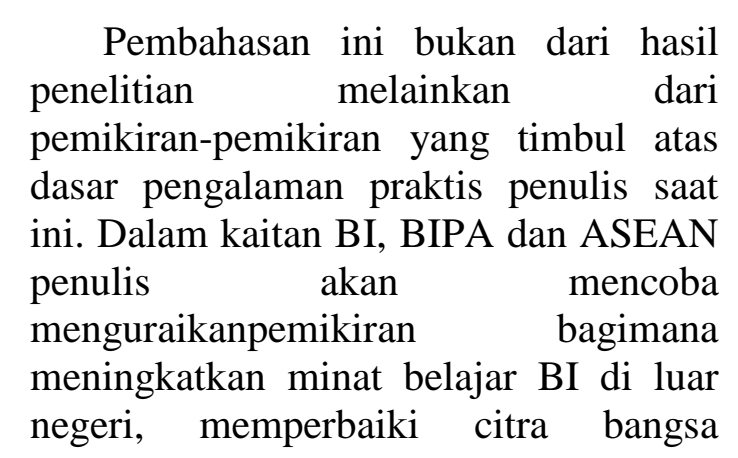

Indonesia dan mungkin upaya menjadikan BI menjadi bahasa lingua franca di ASEAN. Hal ini penulis maksudkan agar dapat diperoleh sebuah garis temu dari suatu opini (cita-cita) dan fakta yang disatukan oleh BI.

\section{HASIL DAN PEMBAHASAN \\ 1. Pengajaran Bahasa Indonesia di Thailand}

Rivai, dkk. (2010:1) dalam studi Pemetaan Pengajaran Bahasa Indonesia bagi Penutur Asing (BIPA) di Asia, mengatakan bahwa banyak hal yang menyebabkan orang asing ingin belajar BI sebagai alat untuk mencapai berbagai tujuan. Rivai, dkk. juga mengatakan BI merupakan salah satu bahasa di dunia yang berkembang pesat di abad ke-20, pengajaran BI terus mengalami peningkatan di luar negeri. Dengan berkembangnya hubungan antara Indonesia, ASEAN dan Negara lain dalam berbagai bidang, makin besar dirasakan perlunya orang asing belajar BI. Hal serupa saat ini yang terjadi di Thailand yaitu meningkatnya jumlah penyelengara dan pembelajar BIPA. Dengan tujuan untuk mempersiapkan diri menyambut Komunitas ASEAN pada tahun 2015 mendatang. Ini dapat dilihat dari jumlah perguruan tinggi yang membuka program BIPA.

Pengajaran BI di Thailand disambut baik oleh pelaku pendidikan di Thailand khususnya di Perguruan 
Tinggi. Ada delapan Perguruan Tinggi Thailand yang membuka mata kuliah pilihan bahasa Indonesia diantaranya Neresuan Universty, Chulalongkorn University,Mae Fah Luang University, dan Ciangmai University. BI sebagai mata kuliah pilihan bahasa asing di NU menjadi salah satu mata kuliah pilihan yang banyak peminatnya. Dengan adanya Komunitas ASEAN yang di targetkan terwujud dalam tahun 2015 BI mulai serius di pelajarai oleh mahasiswa Thailand khususnya di NU. Ini membuktikan bahwa BI dapat diteriman di wilayah Thailand dengan tangan terbuka yang secara berlahan namun pasti sudah menyebar di universitas-universitas di wilayah Thailand dan terakhir Universitas Mae Fah Luang di wilayah Thailand Utara.

Walaupun umumnya BI di Thailand masih dalam bentuk mata kuliah pilihan bahasa asing dan mempelajari BI untuk kepentingan diplomasi, ini sudah menunjukkan kemajuan yang bagus untuk perkembangan BI di Thailand. Adanya tujuan untuk menambah pengetahuan orang asing khususnya orang Thailand tentang BI merupakan langkah awal bagi Indonesia untuk meningkatkan citra Indonesia di mata Thailand. Dalam kondisi demikian, secara langsung program dan sistem pembelajaran BIPA diperlukan dalam memenuhi kebutuhan orang Thai untuk mengenal Indonesia dan sebaliknya untuk mempersiapkan diri dalam komunitas ASEAN.

Pembelajaran BI di NU sudah berlangsung sejak tahun 1999 (2524 dalam tahun Thailand) yang diajarkan oleh dosen berkebangsaan Thailand Asst. Prof. Siriporn Maneechukate. Pada tahun 2011 BI dihidupkan lagi oleh kampus untuk tujuan Komunitas ASEAN. Adanya peningkatan pemilihan BI oleh mahasiswa Strata Satu (S-1) yang memilih BI sebagai mata kuliah pilihan bahasa asing. Dan karena alasan Komunitas ASEAN juga mahasiswa pascasarjana, staf, dan masyarakat umum mengikuti kursus BI di Naresuan Universitu Language Center (NULC). Menunjukkan bahwa BI di NU sudah mendapat tempat tersendiri. Program BI yang adalah BIPA, di NU dilaksanakan dalam bentuk mata kuliah pilihan yaitu minor course dan elective course. Mata kuliah pilihan BI ini dapat di pilih oleh seluruh mahasiswa NU setiap semesternya. Kurikulum BI yang penulis siapkan dan ajarkan saat itu sesuia dengan kurikulum mata kuliah minor yang ada pada level A (dasar) dan B (lanjut). Karena ini mata kuliah pilihan, mahasiswanya lebih dari 20 orang sehingga penulis mengunakan metode pembelajaran sistem kelas dan metode langsung dengan media grafis.

Oleh karena itu, pembelajaran BIPA memiliki peranan penting dalam perkembangan bahasa dan studi Indonesia di luar negeri. Karena BIPA 
mejadikan BI memiliki progress di kancah Internasional. Seperti yang dikemukakan oleh I Gede Artika (dalam Purwanti, 2007) bahwa dalam kedudukanya sebagai bahasa nasional, kehadiran BI dapat diterima oleh seluruh warga suku bangsa dengan tangan terbuka.

Saat penulis bertanya kepada mahasiswa S-1 yang memilih mata kuliah pilihan BI, diantaranya mereka mengatakan bahwa BI mudah untuk dipelajari, hurufnya huruf latin yang sama dengan Bahasa Inggris sehingga ejaannya tidak sulit, tata bunyinya yang tidak memiliki intonasi, kosakata dan tata bahasanya yang tidak sulit. Bagi mahasiswa Thai, mempelajari BI tidak sesulit mempelajari bahasa Thai (Thailand) itu sendiri, bahasa Burma (Myanmar), bahasa Lao (Laos), bahasa Khmer (Kamboja), bahasa Vietnam dan bahasa Tagalog (Filipina). Ini juga dikatakan -diakui- oleh pengajarThai yang mengajar BI di NU. Tentunya jawaban pembelajar BIPA tersebut merujuk pada ragam rendah BI yang biasa di pakai dalam ragam lisan atau ujaran. Minsalnya, percakapan sehari-hari seperti salam dan ucapan perpisahan, di pasar dalam tawar menawar, dan di dalam percakapan yang akrab denganteman sebaya.Karena, di dalam ragam lisan yang penutur bahasanya bersemuka yang unsur gramatikal seperti fungsi subjek, predikat, dan objek dan hubungan di antara fungsi itu kadang-kadang dapat dilesapkan.Oleh karena itu, dikatakannyamudah mempelajari ujaran BI juga menjadi peluang dalam upaya memposisikan BI sebagai salah satu bahasa di ASEAN dan dunia yang dapat menjembatani keberlangsungan kehidupan berbangsa.

Ihwal terkait dengan adanya sebuah wacana tentang usulan agar BI menjadi bahasa resmi dan bahasa kerja the second language di ASEAN pada KTT ASEAN tahun 2011 saat Indonesia menjadi tuan rumah. Isu wacana tersebut menarik perhatian penulis, berkaitan dengan pengalaman praktis penulis. Penulis berpikir, melalui pembelajaran BIPA mampu mengawali menjadi media diplomasi dalam menjembatani BI menjadi bahasa lingua francadi ASEAN, mengingat Indonesia memiliki hubungan diplomasi dan berperan penting di dalam ASEAN. Dan BI pada masa depan dicita-citakan bukan hanya menjadi bahasa negara, tapi juga harus mampu menjadi bahasa dari komunitas yang mengglobal, selama bahasa dapat memenuhi tuntutan untuk mengakomodasikan perubahan dan penyesuan-penyesuan (Purwanti, 2007:114) dalam makalahnya Pengajaran BIPA sebagai Media Komunikasi Lintas Budaya.Berangkat dari hal itu, sikap positif yang diharapkan untuk BI adalah 1) bangga berbahasa Nasional, BI 2) mempunyai rasa setia bahasa, dan 3) merasa 
bertanggung jawab atas perkembangan BI.

\section{Komunitas ASEAN}

ASEAN didirikan bermula dari hasrat untuk menciptakan kawasan yang damai. Negara-negara penandatanganan deklarasi Bangkok menginginkan kerja sama untuk mencapai pertumbuhan ekonomi, perkembangan sosial-budaya, serta perdamaian, dan stabilitas dalam wadah ASEAN. ASEAN merupakan perhimpunan bangsa-bangsa di Asia Tenggara yang didirikan pada tanggal 8 Agustus 1967 di Bangkok Thailand melalui penandatanganan Deklarasi Bangkok oleh Menteri Luar Negeri Filipina, Indonesia, Thailand, Malaysia, dan Singapura. Selanjutnya untuk merealisa-sikan harapan tersebut, ASEAN mengesahkan Bali Concord II pada Konferensi Tingkat Tinggi (KTT)ASEAN ke-9 di Bali tahun 2003 yang menyepakati pembentukan Komunitas ASEAN (ASEAN Selayang Pandang, 2010).

Komunitas ASEAN terdiri atas tiga pilar, yaitu Kominitas Politik-Keamanan ASEAN (ASEAN political_security Community/ APSC), Komunitas Ekonomi ASEAN (ASEAN Economic Community/ AEC), dan Komunitas Sosial Budaya ASEAN (ASEAN Social_Cultural Community/ ASCC). Semenjak ditandatanganinya piagam ASEAN pada KTT ke-13
ASEAN pada tanggal 20 November 2007 di Singapura oleh 10 Kepala Negara/Pemerintahan Negara Anggota ASEAN, tambah memperkuat hasrat perhimpunan bangsa-bangsa di Asia Tenggara tersebut untuk mewujudkan kerja sama antar anggota dan membentuk perdagangan bebas. Untuk mewujudkan keingin tersebut ketiga Pilar komunitas ASEAN sedang galak dikerjakan. Khususnya di Thailand, penulis merasakan gaung Komunitas ASEAN sangat terasa dari pada Indonesia. Pemerintahan dan Masyarakat Thailand berlomba-lomba bekerja sama untuk menpersiapkan diri untuk Komunitas ASEAN 2015.

Salah satu imbas dari pilar komunitas sosial budaya ASEAN tersebut adalah bahasa. Saat Komunita ASEAN terjadi nanti 2015, bahasa memainkan peran yang sangat penting pada pasar bebas Komunitas ASEAN. Perkembangan ketiga pilar Komunitas ASEAN tersebut menuntut anggotanya mempunyai kemampuan berbahasa dengan baik. Oleh karena itu, gambaran ini sangat jelas memperlihatkan bahwa BI di Thailand satu diantara bahasa asing yang dipelajari di Perguruan Tinggi.

Bahasa yang digunakan dalam pertemuan ASEA, pastinya adalah bahasa Inggris yang merupakan bahasa internasional. Tapi baru-baru ini Adanya "selentingan wacana" yang mengusulkan bahwa bahasa Indonesia menjadi bahasa resmi dan bahasa kerjasama di tingkat 
ASEAN. Usulan ini muncul ketika Indonesia menjadi tuan rumah KTT ASEAN pada Tahun 2011 lalu yang di informasikan oleh berbagai sumber dari media elektronik (http://stppmalang. ac.id/index.php/component/content/ article/68-artikel/183-bahasa, diakses 6 Juni 2013). Penulis mencermati bahwa wacana ini muncul bentuk dari peran aktif Indonesia dalam Deklarasi Mengenai Persatuan ASEAN dalam Keragaman Kebudayaan: Menuju Penguatan Komunitas ASEAN (Declaration on ASEAN Unity in Cultural Diversity: Towards Strengthening ASEAN Community) yang ditandatangani para Mentri kebudayaan Negara anggota ASEAN di KTT ke-19 ASEAN 2011.

Berangkat dari opini ini penulis berpikir bahwa wacana tersebut sangat bagus bagi keberadaan bangsa dan Negara Indonesia dan ASEAN mengingat untuk memperlancar terjadinya proses kerjasama yang nanti diperankan sepenuhnya oleh masyarakat anggota ASEAN melalui Komunitas Ekonomi ASEAN (KEA/ AEC). Untuk itu, untuk mempersiapkan masyarakat Indonesia terjun ke Komunitas ASEAN, KEA, Indonesia dan ASEAN sudah sepantasnya memfasilitasi bahasa yang akan digunakan oleh pelaku Komunitas-komunitas tersebut. Tidak hanya itu, dilihatdari segi pilar Komunitas Sosial Budaya ASEAN adanya program Darmasiswa yang merupakan program beasiswa parsial untuk mahasiswa asing _yang tidak hanya ASEAN_ dari berbagai negara yang tertarik mempelajari BI, kesenian, musik, kuliner, dan kerajinan tangan khas Indonesia yang sangat intensif setiap tahunnya. Hal ini dapat memperkuat alasan penulis untuk mengatakan bahwa BI bisa menjadi bahasa lingua franca di kawasan ASEAN.

Bahasa lingau franca merupakan bahasa perantara yang digunakan secara sistematis untuk tujuan perhubungan antara orang-orang yang tidak sama bahasa ibunya. Lingua franca diartikan berdasarkan fungisnya, tanpa melihat sejarah atau srtuktur bahasanya (Viacheslav A. Chirikba, dalam Muysken, P. 2008). Di dalam sejarah manusia pemilihan suatu bahasa sebagai lingua franca, yakni bahasa perantara orang yang latar budayanya berbeda, bahasa kebangsaan, atau bahasa internasional tidak pernah dibimbing oleh pertimbangan linguistik, logika atau estetika tetapi selalu oleh patokan politik, ekonomi dan demografi (Alwi $\mathrm{H}$. dkk, 2003;2-3). Jadi yang dimaksud dengan linga franca adalah sebuah sistem linguistik yang digunakan sebagai alat komunikasi sementara oleh para partisipan yang mempunyai bahasa ibu yang berbeda untuk kepentingan politik, ekonomi dan demografi. 


Kita sudah melihat bahwa BI
bebagai
memperhubungkan semua penutur
berbagai dialek bahasa di Indonesia. BI
mempersatukan bangsa Indonesia
menjadi satu masyarakat bahasa dari
Sabang sampai ke Merauke. Menilik
pada etnografi BI yang adalah bahasa
rumpun melayu yang secara langsung
banyak di pengaruhi oleh bahasa Melayu
dan di gunakan juga di Negara Malaysia,
Brunei Darussalam, Singgapur salah satu
dari empat bahasa rasminya, dan
Thailand Selatan, yaitu di propinsi Yala,
Pattani dan Narathiwat.
Ragam BI yakni tata bunyi, tata
bentuk, dan tata kalimat BI masih sangat banyak persamaanya dengan padanannya di dalam bahasa Melayu -walaupun logat BI sudah jauh berbeda dari bahasa melayu aslinya-. Perbedaanya terletak pada lafal dan kosakatanya. Jika orang Indonesia dan orang melayu (Malaysia, Brune, dan Thailand Selatan) mengunakan bahasanya masing-masing, bagian yang dapat dipahami jauh lebih besar daripada bagian yang tidak (Alwi, H. 2003:20). Karena kita masih sama-sama menyerap bahasa Melayu dan Sanskerta-yang bahkan sama dengan bahasa di Negara Asia Tenggara lainnya seperti bahasa Thai, yang masih banyak menyerap bahasa Sanskerta-,seperti nama, warna dan hari (dalam Notosudirjo, 1990). Yang dalam bahasa Thai juga diserap dari bahasa sanskerta yaitu menjadi nam, wan dan hari (yang artinya nama lain dari Dewa Wisynu).

Alasan lain juga diperkuat oleh beberapa hal: 1. Bahasa Indonesia adalah bahasa yang paling banyak digunakan di kawasan ASEAN mengingat $43 \%$ penduduk ASEAN adalah masyarakat Indonesia (http://whatindonews. com/id/post/3725, diakses 25 Juli 2013). 2. Pada desember 2007, Pemerintah Daerah Ho Chi Minh City mengumumkan bahasa Indonesia sebagai bahasa kedua secara resmi dan Vietnam merupakan anggota ASEAN pertama yang menetapkan bahasa Indonesia sebagai bahasa resmi kedua di negaranya (Kompas, Edisi Jumat 6 Mei 2011). 3. Di Thailand sudah banyak Perguruan Tinggi yang melaksanakan program bahasa Indonesia. Dan merupakan program bahasa asing Asia Tenggara yang dipilih sebagai matakuliah pilihan mahasiswa.

Dari beberapa fakta dan asumsi di atas, penulis merasa yakin bahwa BI bisa dan mampu untuk menjadi bahasa lingua franca di ASEAN.Ini merupakan patisipatif Indonesia dalam menyukseskan tujuan dari Komunitas ASEAN sebagai negara terbesar di Asia tenggara. Dijadikanya BI sebagai bahasa lingua franca di ASEAN, Indonesia dapat mengenalkan budaya dan mengembangkan citra positif masyarakat, yang lambat-laun akan dikenal oleh dunia internasioanl lebih baik lagi. Karena melalui BI kita dapat 
mengenalkan negara, budaya, dan kehidupan masyarakat Indonesia dengan lebih baik. Dan akan mendukung perekonomian bangsa Indonesia. Pemerintah dan masyarakat Indonesia harus siap untuk mengemban tugas yang mulia ini dari bentuk perjuangan pemuda Indonesia pada Sumpah Pemuda 28 Oktober 1928.

Oleh karena itu, untuk mewujudkan BI menjadi bahasa lingua franca pengajaran dan pembelajaran BIPA pada sistem pengajaran BIPA, materi pengajaran dan bahkan program pengajaran BIPA di negara ASEAN harus di perbaiki sesuai dengan tujuan pembelajaran BIPA untuk lingua franca. Yang paling utama adalah tujuan dalam pembelajaran BIPA harus diubah menjadi sebuah tujuan pembalajaran BI untuk bahasa lingua franca. Sistemnya tidak hanya sebagai program mata kuliah pilihan di universitas tetapi mejadi sebuah program dalam visi dan misi menjadikan BI menjadi bahasa perantara di kawasan ASEAN.

\section{Pengajarandan Pembelajaran BIPA}

\subsection{Sistem Pengajaran}

Tidak penulis pungkiri terjadinya beberapa kendala dalam pengajaran BIPA yang mengakibatkan menurunya minat orang asing untuk mempelajari BI. Menurut penulis, masalah tersebut perlu disikapi, dibahasa dan dicarikan jalan keluarnya. Mungkin salah satu faktornya adalah kurang gencarnya penyelenggaraan BIPA di dalam maupun di luar negeri dan jatuhnya citra Indonesia di mata internasioanal. Di berbagai tempat pengajaran BIPA memiliki kendalanya masing-masing. Dengan berbagai alasan mereka kemukaan diantara masalah sistem pegajaran dan materi pegajaran.

Dalam sistem Pengajaran BIPA bagi pembelajar bahasa adalah proses penguasaan bahasa asing (bahasa kedua). Hal ini harus disadari oleh pengajar BIPA agar permasalahan-permasalahan yang di hadapi pembelajar bahasa kedua bisa dihadapi dan di carikan pemecahannya. Dalam menguasai bahasa kedua (second language), pembelajar bahasa kedua dihadapkan pada proses pembelajaran (second language learning) dan proses pemerolehan bahasa (second language acquisition). Proses pembelajaran bahasa kedua dan pemerolehan bahasa kedua mempunyai dampak yang kuat terhadap penguasaan bahasa pembelajar. Pengajaran mendorong pembelajar untuk mampu mempelajari kaidah-kaidah bahasa sebagai dasar keterampilan untuk berkomunikasi, dan ini tidak mudah.

Kebutuhan pembelajaran di tingkat dasar secara garis besar adalah menguasai kosakata, ekspresi-ekpresi sederhana agar mampu menyampaikan dan meminta informasi tentang topik-topik keseharian. Bentuk 
kebahasaan yang bisa kita berikan adalah kosakata bentuk dasar, kata-kata tugas, kata hubung sederhana, strukur kalimat sederhana. Bentuk intruksionalnya adalah memperkenalkan diri, tanya jawab aktivitas sehari-hari, menanyakan arah dan tempat, menawarkan dan memesan, mempersilahkan dan meminta tolong, bercerita dan berdiskusi. Di tingkat lanjut, kebutuhan pembelajaran lebih kompleks. Pembelajar membutuhkan penguasaan kaidah-kaidah tata bahasa, struktur kalimat yang kompleks, dan kosakata yang lebih kompleks. Tujuan yang ingin di capai pada tingkat lanjut adalah mengembangkan keterampilan berbahasa yang cukup tinggi.

Kebutuhan penguasaan bahasa yang ingin di capai oleh pembelajar BIPA harus di ketahui oleh pengajar BIPA terlebih dahulu. Ini berhubungan dengan sistem dan materi-materi pilihan yang akan di ajarkan nantinya serta hasil akhir yang diharapkan. Oleh karena itu, latar belakang pengetahuan pembelajar terhadap bahasa target yaitu BI harus di ketahui oleh pengajar. Seperti yang dikatakan oleh Littlewood (1981:6) menyarankan beberapa keterampilan berbahasa yang harus dilatih dan dikuasai oleh pembelajar sehingga kelas bahasa menjadi lebih komunikatif, yaitu:

a. Pembelajaran harus mencapai kompotensi linguistik setinggi mungkin. Hal ini dapat dicapai dengan pengembangan keterampilan "memanipulasi" system linguistic kearah pemakaina bahasa untuk mengekspresikan berbagai maksud.

b. Pembelajar dapat membedakan bentuk-bentuk kebahasaan untuk memperkaya kompetensi linguistiknya dengan bentuk-bentuk kebahasaan untuk tujuan komunikasi.

c. pembelajar harus mengembangkan keterampilan dan strategi penggunaan bahasa untuk menciptakan makna secara efektifd dan situasi yang kongkrit.

d. pembelajaran harus menyadari makna sosial dari bentuk-bentuk bahasa sehingga dapat menerapkanya dalam berbagai situasi sosial.

Sistem pengajaran BIPA di luar negeri dapat mengunakan beberapa metode diantaranya mengunakan metode langsung, metode terjemahan, metode audiolingual, dan metode pendekatan komunikatif. Metode langsung adalah metode yang dipelajari melalui asosiasi langsung antara kata dan frasa dengan benda dan aksi (gerak-gerik) tanpa intervensi bahasa ibu. Metode terjemahan adalah metode yang menterjemahkan bahasa target ke dalam bahasa pembelajar, metode ini akan sangat sulit jika pelajar BIPA berasal dari berbagai Negara dan tidak bisa berbahasa Inggris atau pengajar tidak bisa berbahasa pembelajarnya. Metode audiolingual adalah metode pengajaran dengan sistem pengembangan keempat aspek kemampuan berbahasa secara 
alami, dan metodeini dapat dilakukan pada pemebelajaran tingkat lanjut. Dan sedangkan metode pendekatan komunikasi adalah mengajarkan bahasa berperan sebagai alat komunikasi (Fachrurrozi dan Mahyuddin, 2011).

Penulis lebih senang dan cenderung mengunakan metode langsung dan metode pendekatan komunikasi dalam mengajar di NU. Metode langsung yang dikembangkan oleh Berlitz dan Jespersen pada abad ke-19, yang membutuhkan keseriusan dalam mendengarkan, mengartikan dan berbicara. Karena BI dipelajari melalui asosiasi langsung antara kata dan frasa dengan benda dan aksi (gerak-gerik) tanpa intervensi bahasa Thai. Metode tersebut tentunya penulis sesuaikan dengan media pembelajaran. Untuk pembelajaran tingkat dasar penulis kuatkan dengan metode pendekatan komunikasi yaitu komunikasi secara lisan untuk melatih kemampuan mengunakan kosakata yang telah di pelajari dalam kegiatan mendengarkan dan berbicara.

\subsection{Media Pembelajaran}

Media pembelajaran yang dapat digunakan oleh pengajar diluar negeri dapat mengunakan berbagai media. Media adalah berbagai jenis komponen sebagai pengantar informasi dari sumber pesan ke penerima pesan. Fungsi media pembelajaran diantaranya ada tiga yaitu 1) memperjelas penyajian informasi, 2) mengatasi keterbatasan ruang, waktu dan daya indra, 3) mengatasi sifat pasif pembelajaran yang membangkitkan motivasi belajar dan menimbulkan kegairahan belajar.

Ada beberapa media pembelajaran yang dapat digunakan oleh pengajar luar negeri diantaranya yaitu, 1) media grafis, 2) media audio, 3) media audio-visual, 4) permainan simulasi dan 5) lingkungan sekitar. Media grafis adalah semua media berbetuk grafika yang terutama digunakan dalam pembelajaran kosakata, berbicara, tatabahasa, dan menulis. Media grafis itu bisa berupa foto, sketsa, denah, karikatur berangkai, peta/ globe, poster, majalah atau surat kabar dan lain-lain (Sadiman, 1990)

Media permainan dan simulasi adalah media yang digunakan untuk dimainkan atau didemonstrasikan. Terutama digunakan untuk pembelajaran kosakata dan berbicara. Seperti kartu, pakain tradisonal dan masakan tradisional. Media Audio adalah media yang disampaikan dengan cara diperdengarkan. Digunakan terutama untuk pengajaran menyimak, kosakata, berbicara dan menulis. Bisa rekaman suara pengajara sendiri dan lagu-lagu yang pendek dan ringan. Media Audio visual adalah media yang dapat dilihat dan dapat diperdengarkan. Diberikan 
terutama dalam pembelajaran menyimak, membaca, kosakata, dan berbicara seperti rekaman siaran televisi di Indonesia secara live streaming dan bisa melalui youtube misalnya iklan. Dan media lingkungan sekitar berupa segala hal yang berada di sekitar siswa berupa keadaan alam, bangunan, peristiwa, yang dapat diberikan untuk pengajaran berbicara, menyimak, kosakata, membaca dan menulis dengan membawa siswa keluar ruangan seperti ke taman, ke perpustakaan dan kantor.

Dengan metode langsung dan komunikasi yang penulis lakukan, media yang sering penulis gunakan adalah media grafis dan media permainan dan simulasi. Untuk tahap awal mengenalkan Indonesia secara umun penulis mengunakan peta, poster atau gambar-gambar untuk memprlihatkan budaya-budaya Indonesia seperti pakaian adat, rumah adat, alat tradisional Indonesia, tari dan alat musik tradisional Indonesia. Mengunakan media grafis untuk memperlihatkan budaya-budaya Indonesia bisa di masukan ke dalam bahan ajar BIPA. Dan untuk tahap selanjutnya penulis megunakan media permainan simulasi dengan permainan tradisonal. Bagi penulis mengajarkan BIPA dengan media-media pembelajaran dalam aktivitas pembelajaran membantu dalam ketercapaian tujuan belajar BIPA dengan maksimal.

\subsection{Materi Pembelajaran yang Menyertakan Pengetahuan Budaya}

Budaya yang ada di sekeliling bahasa dapat di manfaatkan sebagai bahan ajar BIPA tingkat dasar. Misalnya di dalam media pembelajaran pengajar BIPA dapat mengunakan media permainan tradisional seperti permainan ular naga dan congkak dan lain-lain untuk mengajarkan materi memberikan salam (greeting) pada permainan tradisinal ular naga dan mengajarkan materi berhitung pada permainan congkak.

Dibeberapa Negara ASEAN terdapat beberapa bentuk permainan yang sama dengan permainan ular naga yang ada di Indonesia. Permainan ular naga di Thailand bernama ngu kin hang dan permainan congkak atau dakon yang dalam bahasa Thailand adalah maak lum. Dari dua permainan tradisional Indonesia ini yang hampir sama dengan permainan tradisonal di Thailand akan menarik minat pelajar BIPA untuk belajar bahasa dan mengenal budaya Indonesia.

Permainan tradisional ular naga adalah permainan berkelompok yang dimainkan oleh minimal 5-6 orang, 2 orang sebagai pembuat "gerbang" (kiri-kanan), yang lainnya netral berbaris melingkar bergandeng pegang pinggang, yakni anak yang berada di belakang berbaris sambil memegang ujung baju 
atau pinggang anak yang di mukanya. Seorang anak yang lebih besar, atau paling besar, bermain sebagai "induk" dan berada paling depan dalam barisan. "Induk" dan "gerbang" biasanya dipilih dari anak-anak yang tangkas berbicara, karena salah satu daya tarik permainan ini adalah dalam dialog yang mereka lakukan.

Contoh simulasi permainan yang penulis lakukan dalam permaian ular naga. Materi ajar dengan topik salam dan perkenalan. Saat simulasi peran dilaksanakan ada dua orang yang sebagai gerbang dan ada satu orang yang sebagai induk naga dan selebihnya sebagai anak naga. Permainan di mulai dengan bernyanyi.

\section{Ular naga panjangnya, bukan kepalang \\ Menjalar-jalar selalu kian kemari \\ Umpan yang lezat, itulah yang di cari \\ Ini dianya, yang terbelakang}

Saat satu anak naga yang tertangkap yang menjadi gerbang bertanya kepada anak naga.

\section{Dialog 1:}

Gerbang (G1) : Selamat pagi

Anak naga (a) : Selamat pagi

Gerbang (G1) : Anda siapa?

Anak naga (a) : Kenalkan, nama saya Ana. Nama Anda siapa?
Gerbang (G1) : Nama saya Ivan.

Ini teman saya

Gerbang (G2) : Nama saya Kiki.

Apa kabar?

Anak naga (a) : Baik.

Gerbang (G1) : Anda dari mana?

Anak naga (a) : Saya dari

Indonesia.

Gerbang (G2) : Apa asal Anda

dari Indonesia?

Anak naga (a) : Iya, saya dari

Indonesia.

Gerbang (G1) : Baiklah, sampai

jumpa

Anak naga (a) : Sampai jumpa

Gerbang (G2) : Sampai jumpa

\section{Dialog 2:}

Induk naga (a) : Halo, apa kabar?

Gerbang (G1) : Saya baik.

Induk naga (a) : Anda siapa?

Gerbang (G1) : Saya Ivan

Gerbang (G2) : Saya Kiki

Gerbang (G2) : Anda siapa?

Induk naga (a) : Saya Santi, temanya Ana.

Gerbang (G1) : Anda mau

kemana?

Induk naga (a) : Saya dan Ana, mau pergi ke Indonesia

Gerbang (G2) : Oh. Saya dan

Ivan juga ke Indonesia.

Induk naga (a) : Baiklah, sampai jumpa.

Gerbanga (G1,2) : Sampai jumpa.

\section{Monolog:}


Kenalkan, nama saya Ana Khairunisa. Saya berasal dari Indonesia. Di Indonesia saya tinggal di Padang. Saya mahasiswa Universitas Pendidikan Indonesia. Terima kasih.

Dengan teknik pembelajaran dengan media pembelajaran permainan ular naga ini pengajar dapat membuat pembelajar BIPA lebih semangat dan hantu sias. Selain menarik, pengajar dapat menentukantata cara permainan sendiri yang cara pelasanaanya tidak berbeda dengan permainan Ular naga yang sebenarnya. Pengajar harus melakukan beberapahal teknik dalam role play ini terhadap pembelajar yaitu: a) sebelum simulasi dilakukan pembelajar harus mendengarkan instruksi yang di sampaikan oleh pengajar, b) pengajar memperlihatkan video atau youtube permainan tradional ular naga (diputar beberapakali), c) pengajar mengintruksikan simulasi yang akan dilakukan serupa dengan video yang ditonton, d) pembelajar mensimulasikan permianan ular naga susuai dengan materi BIPA saat itu yaitu materi tentang perkenalan.

Aspek yang ditonjolkan dalam pembelajaran berbasis permainan tradisional ini selain aspek budaya adalah aspek kebahasaan yakni pada keterampilan menyimak dan berbicara. Pembelajaran ini diperuntukkan bagi siswa BIPA tingkat dasar. Tujuan umum: 1. Untuk memudahkan pengajar BIPA tingkat dasar dalam mengajarakan materi ajar, 2. Untuk meningkatkan kemampuan mengingat siswa BIPA dalam belajar, 3. sebagai perkenalan tradisi permainan tradisional yang ada di Indonesia.

Untuk contoh lain permainan tradisional yang ada di Indonesia adalah permainan congkak. Permaian congkak atau dakon atau dalam bahada Thai maak lumadalah suatu permainan yang dimainkan oleh 2 orang yang berlawan dengan menggunakan papan dakon yang terdapat 16 lumbung, dimana 14 lumbung kecil dan 2 lumbung besar. Di dalam setiap lumbung ini awalnya diisi oleh 7 buah congkak atau kecik atau batu atau kerang. Dan lumbung besar digunakan sebagai tempat menyimpan batu yang jadi miliknya. Permainan ini dimainkan sampai batu kecil habis dan menghitung batu yang berada di lumbung besar milik setiap pemain.Kosakata yang digunakan pada saat bermain congklak:

1. Batu

2. Lumbung

3. Hitung/berhitung/menghitung

4. Kosong

5. Isi

6. Mulai

7. Berhenti

8. Ambil/mengambil

9. Simpan/menyimpan

10. Satu, dua, tiga, empat, dan seterusnya 
11. Maju

12. Mundur

13. Tambah/bertambah

14. Kurang/berkurang

15. Kalah

16. Menang

Teknik pembelajaran: 1)

Pengajar memperlihatkan alat-alat permainan congkak, 2) Pembelajar menyimak penjelasan pengajar ikhwal permainan congkak, 3) Pembelajar menonton video permainan congkak, 4) Siswa mengumpulkan kata-kata yang disimaknya dari video rekaman dan penjelasan pengajarnya, 5) Pembelajar mempraktikan permainan congkak dengan mempraktikan kata-kata yang mereka peroleh dari rekaman yang mereka tonton. Teknik ini juga dapat memperkenalkan tradisi permainan tradisional yang ada di Indonesia.

Mungkin media permainan simulasi ini hanya dapat di gunakan pada kelas tingkat dasar dan pada usia pembelajar BIPA masih remaja, tapi itulah yang penulis lakukan saat mengajar siswa di Princess Chulabhorn's College Phitsanulok dan di NU Thailand.

\section{SIMPULAN}

Berdasarkan uraian di atas, dapat penulis tarik kesimpulanya bahwa, BI dapat memperbaiki citra Indonesia di ASEAN dengan dijadikanya BI sebagai media diplomasi kebahasaan dan budaya pada Komunitas ASEAN. Sistem dan materi pengajaran BIPA yang menarik minat pembelajar BIPA diluar negeri dapat disesuaikan dengan tujuan pengajaran BIPA dengan mengikutsertakan materi tentang budaya Indonesia seperti permainan tradisional secara intensif. Dan BI dapat memiliki peluang untuk dijadikan bahasa lingua franca di kawasaan ASEAN dengan beberapa pemikiran yaitu, mudahnya mempelajari ragam lisan/ ujaran BI yang tidak sesulit mempelajari bahasa lain di dikawasan negara ASEAN seperti bahasa Thai. BI yang berasal dari rumpun bahasa melayu -dianggap orang berperan sebagai lingua franca sejak dulu- yang pengunanya ada di tiga negara ASEAN dan menyerap beberapa kata dari bahasa Sanskerta yang juga diserap oleh bahasa Thai, Burma, Khmer dan Lao. Itu dapat membantu mempermudah untuk memahami dan mempelajari BI.

Konsep BI sebagai media diplomasi sosial budaya dan komunikasi dalam komunitas ASEAN melalui pegajaran BIPA secara terarah dapat dijadikan wacana baru dan ditekankan dalam pengjaran BIPA. Sebagai orang baru dalam pengajaran BIPA, penulis megharapkan begaimana wacana ini dapat membangkitkan semangat para ahli bahasa, pemerintah dan anak bangsa Indonesia dalam menyikapi hal ini. Adakah kesadaran bahwa BI adalah milik kita dan tanggung jawab kita, hal ini tampaknya belum merata dimiliki 
seluruh warga negara. Tidak salah, jika dikatakan bahwa nasionalisme kita dalam berbahasa masih sangat tipis. Kepekaan kita terhadap bahasa yang kita pakai selama ini belum terlihat nyata.

\section{DAFTAR PUSTAKA}

Alwi, H., dkk. (2003). Tata Bahasa Baku Bahasa Indonesia, Edisi Ketiga. Jakarta: Balai Bahasa.

ASEAN Selayang pandang. Edisi Ke-19. (2010). Jakarta Pusat.

Fachrurrozi, A. \& Mahyuddin E. (2011). Pembelajaran Bahasa Asing; Metode Tradisional \&Kontemporer. Jakarta: Bania Publishing.

Lapoliwa, H. (1996). BIPA dan Pembinaan Citra Bahasa Indonesia. Makalah dalam konferensi Internasional II Pengajaran Bahasa Indonesia bagi Penutur Asing (KIP BIPA II). IKIP Padang

Littlewood, W. (1981). Communicative Language Teaching: An introduction. London: Cambridge University Press.

Muysken, P. (2008). Dalam From Linguistic Areas to Areal Linguistics, 2008. Malaysia.

Notosudirjo, S. (1990). Kosakata Bahasa Indonesia. Yogyakarta: Kanisius.

Poerwanti, E. (2007). Pengajaran BIPA sebagai Media Komunikasi Lintas Budaya. Makalah dalam Seminar dan Lokakarya Internasional
Pengajaran BIPA. Jakarta: Pusat Bahasa.

Pusat bahasa. (2007). Mengalang Citra Indonesia melalui BIPA. Kumpulan Makalah Seminar dan Lokakarya Internasional Pengajaran BIPA. Jakarta: Departemen Pendidikan Nasional.

Rivai, O. S., dkk (2010). Pemetaan Pengajaran Bahasa Indonesia bagi Penutur Asing (BIPA) di Asia; Laporan Akhir Program Insentif Riset bagi Peneliti dan/ atau Perekayasa. Jakarta: Pusat Bahasa.

Sadirman. (2011). Interaksi dan Motivasi Belajar Mengajar Mengajar. Jakarta: Rajagrafindo Persada.

Sadiman, A.S., dkk. (1990). Media Pendidikan (pengertian, pengembangan, dan pemanfaatannya). Jakarta: $\mathrm{CV}$. Rajawali.

Soedarsono, S. (2008). Membangun Kembali Jati Diri Bangsa(Yayasan Jati Diri Bangsa). Jakarta: PT Elex Media Komputindo.

(http://stppmalang.ac.id/index.php/comp onent/content/article/68-artikel/183-baha

sa).Diakses 6 Juni 2013 (http://whatindonews.com/id/post/3725). Diakses 25 Juli 2013 